\title{
Stealing Bread and Sleeping Beneath Bridges - Indirect Discrimination as Disadvantageous Equal Treatment
}

\begin{abstract}
The article analyses the concept of indirect discrimination, arguing first that existing conceptualisations are unsatisfactory and second that it is best understood as equal treatment that is disadvantageous to the discriminatees because of their group-membership. I explore four ways of further refining the definition, arguing that only an added condition of moral wrongness is at once plausible and helpful, but that it entails a number of new problems that may outweigh its benefits. Finally, I suggest that the moral wrongness of indirect discrimination is best accounted for in terms of the harm it does to discriminatees, and sketch three ways in which it may do so. I conclude that the analysis provides both a clearer understanding of the concept of indirect discrimination as well as indirect support for a harm-based account of the wrongness of discrimination, while suggesting that our moral obligations qua non-discrimination may be more extensive than is frequently assumed.
\end{abstract}

\section{Direct and Indirect Discrimination}

Discrimination has become an increasingly prominent topic of both political and public debate in the past decades, and perhaps as a result thereof has received renewed scholarly attention. Although still underdeveloped in the philosophical literature, recent years have seen fruitful discussion that has both clarified discrimination conceptually and explored different accounts of what can make discrimination morally wrong. (Radcliffe Richards 2000; Halldenius 2005; Arneson 2006; Edmonds 2006; Lippert-Rasmussen 2006; Heinrichs 2007; Lippert-Rasmussen 2007; Hellman 2008; Lippert-Rasmussen 2008; Moreau 2010; Altman 2011; Segall 2012; Lippert-Rasmussen 2013)

However, comparatively little attention has been granted to indirect discrimination, despite the fact that such cases are today perhaps more common than cases of direct discrimination, given that many of the most grievous forms of direct discrimination have become subject to both prohibitory norms and legal sanction. Furthermore, indirect discrimination is difficult to define, and its moral features controversial.

Conventionally, and here in the words of the European Commission's Department of Employment, Social Affairs and Equal Opportunities, indirect discrimination is understood to 
occur: "When an apparently neutral specification, criteria or practice would disadvantage people on the grounds of racial or ethnic origin, religion or belief, disability, age or sexual orientation..."1 (Campaign 2003) This is less clear than one could wish. There is also reason to doubt that it is accurate. First, because it would not label an actually (rather than apparently) neutral practice that disadvantaged persons on the grounds of group-membership as indirect discrimination; second, because it would label a practice that is in fact classical direct discrimination as indirect discrimination, so long as sufficient deception is provided to make it appear neutral. ${ }^{2}$

Similar problems afflict the academic literature. In a ground-breaking article on discrimination Kasper Lippert-Rasmussen broaches the subject only to say that: "Indirect discrimination occurs whenever an individual, institution, or practice acts in such a way that the interests of some individuals are systematically favoured and yet this does not involve direct discrimination." (Lippert-Rasmussen 2006) In another recent article on the grounds for legal prohibition of indirect discrimination, Oran Doyle takes as his starting point simply the definition that "'Indirect discrimination' connotes a measure that does not on its face distinguish between class $\mathrm{A}$ and class B but which, for some related reason, is nevertheless considered troubling." (Doyle 2007) And finally, despite several pages of discussion, Andrew Altman's recent encyclopaedia entry does not get closer to a definition than that indirect discrimination concerns: “...those [cases] in which acts or policies are not aimed-explicitly or surreptitiously, consciously or unconsciously- at persons for being members of a certain social group. Yet, the acts or policies have the effect of disproportionately disadvantaging the members of a particular group."3 (Altman 2011)

\footnotetext{
${ }^{1}$ Note that, somewhat surprisingly, and inconveniently given the example I later present in Mogul Misogynist, the list does not contain gender. Gender is, however, a standard property on every other such list that I am familiar with.

2 Suppose, borrowing an example from the so-called Tamil-scandal that brought down a Conservative Danish government in 1993, that the Minister in charge of granting refugee status publicly claims that the procedure for doing so treats all applicants equally and fairly, while in reality, and by the express order of the Minister claiming the opposite, the Ministry discriminates against Tamil asylum-seekers. Calling this a case of indirect discrimination, as the definition would seem to require that we do, does not sound right.

${ }^{3}$ Cf. also John Gardner: "Indirect discrimination occurs when someone applies unjustifiable standards which people of one sex or race find it harder to comply with than people of another, to the detriment of someone who is a member of the former sex or race." Gardner, J. (1996). "Discrimination as Injustice." Oxford Journal of Legal Studies 16:3: 353-367. Gertrude Ezorsky: "Institutional discrimination is exemplified when an organization (e.g. a business firm) uses an intrinsically bias-free selection procedure that has disproportional adverse impact on minorities or women.” Ezorsky, G. (2001). Discrimination. Encyclopedia of Ethics. C. B. Becker and L. C. Becker. New York, Routledge: 413-416. Lena
} 
What I want to argue in the following is first that existing conceptualisations of indirect discrimination are unsatisfactory. Second, that indirect discrimination is best conceived as equal treatment that is disadvantageous to the discriminatees because of their group-membership. Third, that while this definition cannot cleanly separate direct and indirect discrimination, three candidate-conditions that might do so, relevance, protected-groups and intentions, fail. Fourth, that while an added condition of moral wrongness is at once plausible and helpful, it entails a number of new problems that may outweigh its benefits. And fifth, that the moral wrongness of indirect discrimination is plausibly accounted for in terms of the harm it does to discriminatees. I conclude that despite its inability to provide a definition that fully satisfies our definitional desiderata, the analysis provides both a clearer understanding of the concept of indirect discrimination as well as indirect support for a harm-based account of the wrongness of discrimination, while suggesting that our moral obligations qua non-discrimination may be more extensive than is frequently assumed.

\section{Three definitional desiderata}

In analysing a concept such as indirect discrimination we face three definitional desiderata. One is to define the concept so as to best match accepted usage, i.e. how competent language-users understand the concept. The second is to account for the interesting properties of the phenomena referred to by the term. The third is to draw the lines between the concept and phenomena at stake and related concepts and phenomena in a way which will help us separate them in practice, i.e. to emphasize both any significant distinctions and similarities between direct and indirect discrimination.

The first desiderata and the resulting lexical definition is important because we are interested in giving an account of the concept that people use when they speak of indirect discrimination. Diverging from the lexical definition risks talking past the dialectically posited interlocutor, which at best leaves nobody any closer to a clear understanding of indirect discrimination, and at worst confuses the issue.

Halldenius: “...a selection criterion that looks neutral systematically leads to disadvantage for a particular group." Halldenius, L. (2005). "Dissecting Discrimination." Cambridge Quarterly of Healthcare Ethics 14: 455-463. For an excellent critical discussion on such definitions see Lippert-Rasmussen, K. (2013). Born Free and Equal? Oxford, Oxford University Press. 
The second desiderata is important because there is no reason to assume that common usage perfectly tracks the way the most interesting features are distributed among phenomena. Our everyday language need not carve reality at the joints, so to speak, and when it does not we should as a minimum be aware of this, and it may on some occasions be preferable to revise our technical definition of the concept so as to create a better fit between it and the distinctive features of e.g. the moral landscape.

Consider the following examples of three types of cases that might be referred to as indirect discrimination:

Neighbourbood schools. The local council provides both public schooling and school transport for all children. They require, however, that a child attends one of the public schools located within a set, relatively short distance of her home. Some public schools are better than others. Black children predominantly live in areas with worse schools; white children predominantly live in areas with better schools. As a result, black children tend to get inferior education compared to white children.

Parental leave. All jobs are open to all members of both sexes. Employers are required to pay for parental leave of up to six months for either parent. Employers prefer job applicants who are unlikely to require leave, or are likely to require less leave. Women take the majority of parental leave, for both cultural and economic reasons. As a result, women tend to have worse job opportunities than men. ${ }^{4}$

Unisex healthcare. Public healthcare is free and available to all. Hospitals employ male and female doctors in roughly equal proportion, and assign them to treat patients based only on competence and availability. Some religious minorities

\footnotetext{
${ }^{4}$ Note that we should not confuse this with a situation in which there is direct discrimination against women, with the motivation of avoiding the economic burden of paying for parental leave. Such direct discrimination is likely to be rare, and most cases will be irrational or a rationalization of direct discrimination against women on other grounds (e.g. gender biases). This is because even if details are as in the example above, being a woman is by itself a poor proxy for requiring parental leave. A 52-year old mother of three, for example, is exceedingly unlikely to need it, despite being a woman, and a company that directly discriminated against her in the hopes of avoiding the burden of paying for parental leave would be exercising poor judgement (in addition to whatever other wrongs). The example therefore concerns the more rational (in an instrumental, goal-directed sense) case of companies directly discriminating against those likely to need parental leave, and thereby indirectly discriminating against women.
} 
have strong privacy norms concerning interaction with members of the opposite sex outside of marriage. Some treatments involve doctors seeing or handling intimate parts of the body. As a result, some members of these minorities refuse treatment, and some members who do not refuse are shamed by treatment.

Following my suggestion of the twin desiderata of conceptual analysis above, we need to consider two sets of questions with respect to such cases. When we try to define the concept of indirect discrimination, we are on the one hand trying to determine what cases like the above have in common, particularly those shared features that distinguish them from related phenomena, such as direct discrimination. But because discrimination is a concept with strong normative connotations, we also need to consider a separate set of questions: are these cases of morally bad actions/policies? If so, are they all bad to the same extent and for the same reasons? If their wrongness varies, what explains the difference? These are not questions that are easily answered, and initial intuitions might well differ from person to person.

Finally, part of the reason why we want to talk about indirect discrimination is that there are cases that do not seem to involve direct discrimination, but which we would nonetheless like to classify as some form of discrimination. A definition ought to help us determine when and why we should classify a case as direct and when as indirect discrimination. In short, and as Kasper Lippert-Rasmussen suggests, it seems preferable that the distinction between direct and indirect discrimination be at once clear, exclusive and exhaustive. That is, it ought to be easy to tell and unambiguous whether a given case is an instance of one or the other, no case should be an instance of both, and every case should be an instance of one or the other. (Lippert-Rasmussen 2013)

\section{Carving discrimination at the joints}

Let us begin with discrimination in its most basic sense. Paradigmatic discrimination is today widely considered morally wrong - a social evil that should be opposed. It is typically less clear, even to those who strongly condemn discrimination, exactly how to define it, what the moral wrongness consists in and as a result thereof how to asses non-standard cases of discrimination. 
Consider the following example of what I believe is a fairly uncontroversial case of discrimination:

Mogul Misogynist. A factory is purchased by a wealthy financier who reviews the personnel records and finds that about half the workers are male and half female. The mogul then proceeds to order the female workers fired and replaced with male workers.

The actions of the Mogul Misogynist are an example of what is normally called direct discrimination. Direct discrimination against a person or persons with a particular property $\mathrm{P}$ (such as a gender, sexual orientation, ethnicity, etc.) can be roughly defined as occurring iff:

(i) An agent treats a person or persons with P (P-persons) differently than she treats or would treat a person or persons without $\mathrm{P}(\neg \mathrm{P}$-persons),

(ii) the differential treatment is disadvantageous to P-persons, and

(iii) it is because $\neg$ P-persons have $\mathrm{P}$ and $\neg$ P-persons do not that the agent treats P-persons differently than $\neg$ P-persons. ${ }^{5}$

The definition allows us to say that Mogul Misogynist is a case of direct discrimination, given the plausible assumptions that the female workers are disadvantaged by being fired and that their being female is causally efficacious in making the mogul treat them differently. A few things are worth clarifying about the definition, however, its tentative nature notwithstanding.

First, the definition is concerned with discrimination against, rather than discrimination for or discrimination between. The difference between these is, I believe, that the first disadvantages,

\footnotetext{
5 This is a simplified and slightly rephrased version of the definition developed by Kasper Lippert-Rasmussen, whose contributions to the conceptualisation of discrimination are hard to overestimate, cf. Lippert-Rasmussen, K. (2006). "The Badness of Discrimination." Ethical Theory and Moral Practice 9: 167-185, Lippert-Rasmussen, K. (2007). Discrimination: What is it and What Makes it Morally Wrong? New Waves in Applied Ethics. J. Ryberg, C. Wolf and T. S. Petersen. Chippenham and Eastbourne, Palgrave Macmillan: 51-72, Lippert-Rasmussen, K. (2013). Born Free and Equal? Oxford, Oxford University Press. My definition deviates from Lippert-Rasmussen's primarily in discarding the condition that the discrimination affects socially salient groups, for reasons to which I shall presently turn. Note also that it will in most cases suffice that the agent merely believes the persons differentially treated to possess the relevant properties. A racist who insults a person she mistakenly believes to be black would presumably still qualify as discriminating against black persons when doing so. For simplicity's sake, however, and since it is not pertinent to the discussion in the following, I have limited the above definition to the objective version.
} 
the second advantages and the third neither advantages nor disadvantages the discriminatee. I believe that this is the only significant difference between the three, but in the present I shall limit the discussion to discrimination against rather than argue this point.

Second, the necessary causal connection can be specified in various ways. In general it seems to me sufficient to say that it must be counterfactually true that had the discriminatee not possessed $\mathrm{P}$, she would not have been subjected to differential treatment. The condition is necessary in order to avoid labelling as discriminatory cases that coincidentally disadvantage. Consider:

Lottery misogynist. A factory is purchased by a wealthy financier, who reviews the personnel records, and finds that half the workers are male, and half the workers female. He proceeds to order half the workers fired by a method of randomly assigning each worker a number and drawing lottery balls, firing the workers whose numbers are drawn, until only half remain. This results in all of the female workers being dismissed.

Intuitively, this is not a case of direct discrimination against women, whatever its similarities with Mogul Misogynist, because possessing $\mathrm{P}$ (gender) plays no part in determining how persons are treated.

Third, note that the definition is purely descriptive, and that it is compatible with it that there are both cases of permissible and cases of impermissible discrimination. The question of when discrimination is wrong, and what makes it so, is a subsequent question.

Fourth, the disadvantage at stake may be restricted to a particular domain rather than all things considered. Thus, we might want to say that the female employees fired by the Mogul Misogynist are discriminated against with respect to their jobs at his factory even if, incredibly, they are all immediately employed by a different company that offers better wages and working conditions, so that all things considered they benefit from the differential treatment. ${ }^{6}$

\footnotetext{
6 A more complicated issue concerns how such a discrepancy between local and all-things-considered advantage/disadvantage affects the wrongness of the discrimination. On this cf. Lippert-Rasmussen, K. (2013). Born Free and Equal? Oxford, Oxford University Press.
} 


\section{What is so indirect about discrimination?}

So far we have established a working definition of direct discrimination against. Compare this to a variation of the case which, like the three initial cases, seems to constitute indirect rather than direct discrimination:

Inadvertent misogynist. A factory is purchased by a wealthy financier, who orders two new assembly belts installed that will somewhat increase productivity. The height of the assembly belts requires employees to be at least $175 \mathrm{~cm}$ tall. The mogul then proceeds to order those $174 \mathrm{~cm}$ or shorter fired, which results in all of the female workers being dismissed and replaced by male workers. ${ }^{7}$

The facts of the case are not much altered, but what we have in this variation is not a case of direct discrimination against women as we defined it above, because the property that satisfies condition (i) (differential treatment; height) is different from the property that defines women as a group. The second variation would, if interpreted as a form of direct discrimination compatible with the previous definition, be a case of discrimination against "people shorter than $175 \mathrm{~cm}$ ". I suspect that many will also have an intuition that there are, or at least may be, moral differences between the two cases. As I initially suggested, we should like to be able to answer a question with respect to both the conceptual and moral differences, that is, which of the differences between the two cases are decisive in making it a case of indirect rather than direct discrimination, and which of the differences, if any, account for a moral difference between the two cases.

We might take the difference in the properties satisfying conditions i) and ii) as our starting point, and adopt a definition, which holds simply that indirect discrimination against P-persons

\footnotetext{
7 I owe the example to Lena Halldenius. Halldenius, L. (2005). "Dissecting Discrimination." Cambridge Quarterly of Healthcare Ethics 14: 455-463. Note also that these figures are fictitious and could be made up to look any way we want to make the case work, but the assumption that all female employees could lose their jobs used in this scenario is not implausible. Suppose average male height is $180 \mathrm{~cm}$, and average female height is $165 \mathrm{~cm}$. These are relatively close to figures for young adults in Northern Europe and North-America according to Wikipedia. (http://en.wikipedia.org/wiki/Human height) Given a standard deviation of ca. $7 \mathrm{~cm}$ (again according to Wikipedia) this means that only ca. $23,9 \%$ men will be shorter than $175 \mathrm{~cm}$, while ca. $92,4 \%$ of women will be shorter than $175 \mathrm{~cm}$; on average, then, female employees will constitute ca. $79,4 \%$ of those fired. While it is unlikely that any sizeable factory will not employ at least one woman of sufficient height to retain her job, a factory with 30 employees (half male, half female) has a ca. $30,5 \%$ chance of firing every single woman upon installing the assembly belts.
} 
occurs as a consequence of disadvantageous differential treatment of $\mathrm{P}_{1}$-persons, with which group P-persons is either partially or fully co-extensive. Indirect discrimination against a person or persons with a particular property $\mathrm{P}$ could then be preliminarily defined as occurring iff:

(i) An agent treats a person or persons with $\mathrm{P}_{1}$ ( $\mathrm{P}_{1}$-persons) differently than she treats or would treat a person or persons without $\mathrm{P}_{1}\left(\neg \mathrm{P}_{1}\right.$-persons),

(ii) the differential treatment is disadvantageous to $\mathrm{P}_{1}$-persons,

(iii) it is because $\mathrm{P}_{1}$-persons have $\mathrm{P}_{1}$ and $\neg \mathrm{P}_{1}$-persons do not that the agent treats $\mathrm{P}_{1}$-persons differently than $\neg \mathrm{P}_{1}$-persons, and

(iv) the group of P-persons is a(n at least partial) co-extension of the group of P1-persons. $^{8}$

The definition largely mirrors that of direct discrimination, and the comments made above apply here as well. It is capable of explaining why Inadvertent Misogynist is a case of indirect discrimination against women. The mogul differentially treats tall and short persons, disadvantaging the latter by firing them, because they are short, and the group of women is at least partially coextensive with the group of short persons, so women end up disadvantaged as a result.

However, this preliminary definition has several flaws. First, and most importantly, recall the three initial cases that I suggested exemplified situations we might want to describe as indirect discrimination. Obviously, there can be disagreement about this, but I will assume that they, and cases relevantly similar to them, do qualify as such. However, only one of them fits neatly with the above definition. In Parental Leave, the businesses differentially treat job applicants likely to take parental leave and those not likely to do so, which disproportionately disadvantages women (given certain socio-cultural background conditions). But in Neighbourhood Schools, it is unclear whether any children are differentially treated, and if so along which division. It appears, rather, that all children are subject to the same treatment,

\footnotetext{
${ }^{8}$ Note that it may be tempting to require that P1-persons be overrepresented in the group of affected P-persons. I discuss reasons to resist this temptation below, and suggest instead an amendment of condition ii).
} 
although one which imposes slightly different conditions on each of them, in that every child must attend a school within a certain distance of her home. Finally, in Unisex Healthcare, it seems clear that nobody is treated differently - the case explicitly states that all patients are treated the same - even if this disadvantages members of the religious minority, because these are sometimes shamed by medical treatment.

The point to note is that, even in the cases in which two groups are differentially treated, the differentially treated groups are not the groups subject to indirect discrimination. This allows us to say that groups subjected to indirect discrimination in Mogul Misogynist and paternal leave are treated equally, by being subjected to the same directly discriminatory treatment between two other groups, the "likely-to-take-leave" and "shorter-than-175cm" and their respective opposites. Since an equal treatment condition has the added advantage of being able to include cases like Neighbourhood Schools and Unisex Healthcare, it seems preferable to adopt it.

This makes it necessary, however, to draw a clear distinction between cases of differential and equal treatment. ${ }^{\text {We }}$ can choose here between an agent-centred and a patient-centred interpretation of differential treatment. A patient-centred interpretation holds that two actions constitute differential treatment if they are relevantly different for the persons affected by the treatment. An agent-centred interpretation holds that actions constitute differential treatment, if the treatment requires that the agent distinguishes (or attempts to distinguish) between two groups.

The patient-centred interpretation is problematic, I believe, because there is no clear and unambiguous way of specifying when actions are and are not relevantly different. If e.g. an agent serves pork ribs for dinner to her guests, some of which are Jewish, Muslim and vegetarian, has she treated them all equally, by serving the same meal, or has she treated them differently, by serving some of her guests edible food, and serving others inedible food? Both

\footnotetext{
${ }^{9}$ Note that I take differential and equal treatment to be dichotomous, so that two actions constitute equal treatment if they do not meet the condition of whichever interpretation of differential treatment we prefer. Note also that the conceptual distinction I am here concerned falls squarely on the "equal treatment"-side, rather than the "treatment as equals"-side, in Dworkin's crosscutting distinction. Dworkin, R. (2005). Taking Rights Seriously. London, Gerald Duckworth \& Co. Ltd.
} 
are true descriptions of the situation, and there is no obvious way for a patient-centred interpretation to justify preferring one to the other. ${ }^{10}$

The agent-centred interpretation does not have this problem. On this understanding, the agent differentially treats two groups if she attempts to distinguish between the two groups in order to perform different actions with respect to them. This may be to perform two (sets of) actions that are or appear to her to be equally valuable, but it must be to perform two apparently different (sets of) actions. ${ }^{11}$

Given these considerations, a simpler, yet presumably improved definition drops the fourth and revises the first and second conditions, so that they hold that indirect discrimination against Ppersons occurs if:

(i*) An agent treats P-persons equally to how she treats or would treat $\neg$ P-persons,

(ii*) the equal treatment is disadvantageous to P-persons

Some clarification of condition (ii*) is required, however. To see this consider a variation of Inadvertent Misogynist in which the assembly belt resulted in both those shorter than $160 \mathrm{~cm}$ and taller than $195 \mathrm{~cm}$ being fired. If we take "disadvantageous to P-persons" to mean simply that at least one member of the group is made worse off by the treatment, this variation would qualify as indirect discrimination against both women and men given (i*) and (ii*), even if it resulted in exactly one man and one women being fired each. ${ }^{12}$ If on the other hand we require that all members of the group be disadvantaged, we would rule out a variation of Inadvertent Misogynist in which a single woman is tall enough to avoid being fired. This cannot be right.

\footnotetext{
${ }^{10}$ It might be supposed that we could let disadvantage determine whether something is equal or differential treatment, but this is to conflate two separate conditions of discrimination, as is illustrated by the fact that we presumably want to maintain the possibility of describing something as an act of discrimination between two groups, i.e. one that differentially treats them, but disadvantages neither.

${ }^{11}$ Consider an agent who is told to "discriminate between P-persons and $\ulcorner$ P-persons by $\varphi$-ing with respect to P-persons, and $\varphi$-ing with respect to $\ulcorner$-persons". Clearly, although she is ordered to discriminate, her treatment of the two groups does not in fact require her to distinguish between them, not even if it is possible to truthfully redescribe $\varphi$-ing as two different actions, as in the "pork ribs for dinner"-example. On the agent-centred interpretation, she is not, therefore, differentially treating the two groups. On the other hand, an agent who hands out green caramels to girls and yellow caramels to boys may be performing two equally valuable actions, and thus discriminating between them, but she is still differentially treating the two groups, because her actions requires drawing the distinction between them.

${ }^{12}$ We can suppose further, if we like, that it is equally probable for a man to be $195 \mathrm{~cm}$ or taller and for a woman to be $160 \mathrm{~cm}$ or shorter.
} 
What we need is a version of the condition which narrows the scope to those situations in which the distribution of advantages and disadvantages resulting from the treatment are both unequal and overall unfavourable to the discriminatees. ${ }^{13}$

There are two ways in which this could occur, illustrated by Neighbourhood Schools and Unisex Healthcare respectively. In the first, we can assume that the disadvantage for any individual child of attending a bad school is the same whether the child is black or white. But the disadvantages and disadvantages are unequally distributed across the two groups because a far greater proportion of black children are made to attend the worse schools by the treatment. In the second, the effect of the treatment is different on P-persons and $\neg$ P-persons. There is, in slightly different terms, a cost of the treatment that is imposed only on P-persons. ${ }^{14}$

Let us therefore amend (ii*) to:

(ii**) the treatment is disadvantageous to P-persons, in that a) more P-persons than $\neg$ P-persons are negatively affected by the treatment (measured as a proportion of the group) or b) P-persons are more negatively affected than $\neg$ P-persons by the treatment. ${ }^{15}$

A final amendment awaits. The analysis of the equal/differential treatment distinction suggests that the causal connection between possession of property $\mathrm{P}$ and the actions performed by the agent specified by condition (iii) is necessary for treatment to be differential. ${ }^{16} \mathrm{We}$ will need to

\footnotetext{
13 This is sometimes expressed as a condition of disproportionate impact. However, the concept of disproportionate impact is, I believe, in dire need of clarification, and it seems preferable to revise our specification of disadvantage, so as to preserve clarity, if possible. Note also that disproportionality in the context of indirect discrimination may mean several things and may not be necessary on some conceptions of indirect discrimination. Thus, in many legal definitions, there is a limiting condition that the disadvantage created is disproportionate to the discriminator's interests, benefits or needs. This, obviously, is not what we are dealing with here, and in any case seems motivated by the desire to limit legal sanctions to particular cases of indirect discrimination, rather than the proper scope of the concept. I discuss a version of this below, in the shape of a relevance-condition. For criticism of the disproportionality condition cf. Lippert-Rasmussen, K. (2013). Born Free and Equal? Oxford, Oxford University Press. Lippert-Rasmussen's suggested solution avoids the disproportionality impact condition by introducing a disadvantage condition tied to P-persons "relative to other relevant, socially salient groups".

14 Note that I hold this to cover both cases where equal treatment is disadvantageous to all parties but more disadvantageous to P-persons and cases where it is beneficial to all parties, but less beneficial to P-persons, as well as those versions where treatment is neither to one group .

${ }^{15}$ Note that this formulation is compatible with the situation being one in which all P-persons are disadvantaged, while no $\ulcorner$ P-person is disadvantaged. This is merely the limiting case of a completely skewed proportion.

${ }^{16}$ Necessary, but not sufficient. Suppose that the agent, in the "pork ribs for dinner"-example had a choice between serving a vegetarian buffet and the pork ribs, and chose to serve pork ribs because she intended to disadvantage Jews, Muslims and/or vegetarians. In this case P does play a causal role in bringing about the disadvantageous treatment, but it remains
} 
revise (iii) in the definition of indirect discrimination, since our revised definition does not contain differential treatment. One revision would be to simply remove condition (iii), leaving the connection between treatment, disadvantage and $\mathrm{P}$ potentially entirely coincidental, but that does not seem right. Consider again Lottery Misogynist, introduced above. Intuitively, and assuming that it is fair, a lottery such as this does not qualify as a case of discrimination, direct or indirect, even if it happens to disadvantage a particular group. Further, consider:

Idiosyncratic direct discriminator. A factory is purchased by a wealthy financier, who reviews the personnel records, and orders that employees born in even months (February, April, etc.) be fired, while those born in odd months (January, March, etc.) are retained. As it so happens, the fired workers all have long surnames $(3+$ syllables $)$, while those retained have short surnames. ${ }^{17}$

To say that this constitutes direct discrimination against those born in even months may sound slightly odd, or rather, it sounds like a highly peculiar form of discrimination, but it is not nonsensical. To say, on the other hand, that it constitutes indirect discrimination against those with long surnames strikes me as absurd. It just so happened that the persons affected belonged to this group, but surely that does not make it a case of indirect discrimination against them? What seems to be missing is a causal connection between disadvantage and possession of $\mathrm{P}$, to match condition (iii), which does a similar job for direct discrimination. This suggests that we should add:

(iii*) it is because P-persons possess $\mathrm{P}$ that treatment is disadvantageous to them. ${ }^{18}$

equal treatment because the agent need not distinguish between P-persons and $\ulcorner$ P-persons; she can serve everyone the same.

${ }^{17}$ Note that as the size of the group of workers increases, the probability that the workers fired would all share the property of long surnames with each other, and with none of the workers retained, swiftly approaches zero (assuming the correlation with birth months is coincidental). But the probability that they all share some idiosyncratic property remains one (i.e. certainty), given that there is an infinite number of such properties.

18 Given the biconditional in (ii**) there are two possible causal connections. P may make the treatment disadvantageous either because $\mathrm{P}$ makes a person more likely to be negatively affected by the treatment, or because possessing $\mathrm{P}$ makes the effect of the treatment worse. Since this is apparent in the statement of (ii**), I do not include these in the statement of (iii*). 
Central to understanding discrimination in this way is that the discriminatees in cases of direct discrimination are similar in certain pertinent respects, a likeness which is not reflected in the differential treatment, while the discriminatees in cases of indirect discrimination are different in certain pertinent respects, a difference which is not reflected in the equal treatment. What we have then are two kinds of discrimination, the first of which disadvantages persons because the agent differentially treats two relevantly similar groups, and the other of which (disproportionately) disadvantages persons because the agent equally treats two relevantly different groups.

Taking all the above together, I suggest that indirect discrimination against a person or persons with a particular property $\mathrm{P}$ occurs iff:

(i*) An agent treats P-persons equally to how she treats or would treat $\neg$ P-persons,

(ii**) the treatment is disadvantageous to P-persons, in that a) a greater proportion of P-persons than of $\neg$ P-persons are negatively affected by the treatment, or b) P-persons are more severely affected than $\neg$ P-persons by the treatment, and

(iii*) it is because $\mathrm{P}$-persons possess $\mathrm{P}$ that the treatment is disadvantageous to them.

So far, so good - we have established a definition of indirect discrimination that at once fits common usage reasonably well, and highlights relevant features and distinctions. But the definition does not meet the third desiderata.

Consider the two misogynist cases again. A work-place which, as in Inadvertent Misogynist, fires workers below $175 \mathrm{~cm}$ of height is, on the conventional view, not engaging in direct discrimination against short persons. But it will arguably be engaging in indirect discrimination against women, because many more women than men are members of this group, and as such women are disproportionately disadvantaged by the requirement. Why is it not a case of direct discrimination against short persons? Intuitively that seems like an odd thing to say, but it is hard to see how it could not be given the definitions developed so far. 
Furthermore, note that in the both cases, the women affected are exactly the same. So why do we not describe Mogul Misogynist as a case of indirect discrimination against less-than$175 \mathrm{~cm}$ 'ers? The way the definitions above give no reason to prefer one description of the cases to the other flies in the face of our intuition that the cases ought to be about women, not short persons. We strongly feel that we should worry about disadvantageous treatment of women, blacks, muslims, homosexuals, etc., in a way that makes it preferable to describe Mogul Misogynist as a case of direct and Inadvertent Misogynist as a case of indirect discrimination against women, not as respectively indirect and direct discrimination against short persons.

In the following I explore a number of conceptual distinctions that might be presumed to account for the difference. I argue that the first three suggestions fail, but that our intuitions about the wrongness of discrimination can account for at least some of our intuitions about the proper focus of the concept of discrimination.

\section{Does relevance matter?}

There are several ways of limiting the scope of discrimination, which might be thought to satisfy the third desiderata and solve the above problems. One tempting approach is to delimit discrimination in terms of the relevance or irrelevance of the property that distinguishes the persons differentially treated. This is a definitional approach familiar in legal practice, which in many countries holds that disproportionate impact does not constitute indirect discrimination when the selection criterion is subject to “objective justification". (Connolly 2006) That is, e.g. employers are permitted to enforce requirements that disproportionately impact a group when these requirements can be shown to be pertinent to the job in question. Thus, even if more men than women have commercial driver's licences, a trucking company that requires applicants to hold such licences is not considered to indirectly discriminate against women, despite the fact that women will be disproportionately prevented from applying. ${ }^{19}$ Much in vogue in at least Anglo-Saxon legal systems since the famous Griggs vs. Duke Power Company US Supreme Court case, (1971) the requirement of objective justification also has the judicial

\footnotetext{
${ }_{19}$ This is putting it too boldly, perhaps. There is a rich and complex body of law on the objective justification defence in indirect discrimination cases, and in some scenarios it might not apply, even in such intuitively reasonable circumstances as above. I trust, however, that the general principle is clear from the example, and set added legal complications aside for present purposes.
} 
advantage that it circumvents some of the problems attached to alternatives, such as the challenge of demonstrating discriminatory intent. (cf. e.g. McCrudden 1982) Thus, what we may call the relevance condition would hold that it is only when the property that defines the disadvantaged group is irrelevant to how persons ought to be treated, that treatment which meets the other conditions constitutes discrimination.

Whether or not the objective justification approach is the best way of framing legal protection is a separate matter that I shall not consider in the present context. But as a means of conceptually distinguishing direct from indirect discrimination the focus on irrelevance runs into severe problems. First, in the definition of relevance, second, in explaining why treating persons differently for irrelevant reasons should in and of itself make a difference, and finally in distinguishing cases involving more than one irrelevant property.

First, it is far from easy to define the relevance involved in a limiting and independent manner. If we take it to be simply what the involved agents regard as being relevant then it seems clear that pretty much anything can be relevant given the suitable conditions and context of the agents. (cf. Wertheimer 1983)

On the other hand, if we take it to be a more substantive, morally circumscribed notion of relevance, then this raises the challenge of supporting this notion independently while avoiding that we end up simply with a distinction between morally permissible and impermissible forms of differential treatment, in which case we are no longer dealing with a relevance condition. ${ }^{20}$

Third, and most importantly, the irrelevance condition does not seem able to help us distinguish cases of direct from indirect discrimination. Consider Inadvertent Misogynist presumably there is a sense in which height is relevant, in that working the newly installed assembly belts requires a certain height, and we can assume for the sake of argument that this is a kind of relevance sufficient to meet the condition. Does that mean that this is not a case of

\footnotetext{
${ }^{20}$ As I shall return to, this is in fact what I take to be the case. That is, the intuitions that support the relevance-account are best understood as really pointing towards an account that relies on a moralized conception of what is relevant, specifically a welfare-account. Giving an account of the independent importance of relevance is not easy, because intuitively it is not obvious why relevance should make a difference. Surely, if, as in my former example, I am handing out candy, and give girls green-wrapped caramels, and boys yellow-wrapped caramels, then although my differential treatment is based on no relevant difference, and setting aside other potential wrong-making features, such as malicious intentions and causing harm, it seems intuitively absurd to say that I am engaging in a moral wrong.
} 
direct discrimination, but indirect, because the selection criterion which the direct discrimination interpretation would pick out is relevant, or that it is not a case of discrimination at all? The way the condition operates in legal definitions suggests the latter, while our need to distinguish the two forms of discrimination requires the former. Furthermore, and worse, the irrelevance would give us no reason to prefer describing Mogul Misogynist as a case of direct discrimination against women rather than indirect discrimination against persons below $175 \mathrm{~cm}$, because presumably being a woman and being short are equally irrelevant in that scenario.

\section{Do protected groups matter?}

A second suggestion for how to distinguish cases of direct and indirect discrimination is a condition limiting discrimination to particular protected groups. Most legal and political conceptions of discrimination operate, as we saw in the example of the European Commission's definition above, with a list of protected groups which, unlike other groups, can be subject to discrimination. Indirect discrimination is then understood as discrimination which affects one of these groups indirectly. The protected groups condition would thus hold that treatment which meets the other conditions constitutes discrimination only if it disadvantages a protected group, and if so it constitutes discrimination of that disadvantaged group. How to design the list of protected groups is a difficult question, but one prominent suggestion is that we focus on socially salient groups, where social salience is defined as a property which is important across a range of social interactions. (Lippert-Rasmussen 2006; Lippert-Rasmussen 2013) While initially the protected groups condition may look promising, there are reasons to think it cannot solve the problems we have encountered.

First, as I have argued elsewhere, there is reason to be skeptical that we should include a group criterion in the concept of discrimination, since it seems neither to be necessary for a lexical definition nor to map onto a morally relevant difference. [self-reference deleted] Briefly put, it is hard to see why the group-criterion constitutes a conceptual condition, because, although paradigmatic cases of discrimination concern socially salient groups, it seems perfectly sensible to speak of idiosyncratic discrimination, in a way which it does not to speak e.g. of "discrimination against P-persons", which does not disadvantage P-persons, or treats everyone equally. This suggests that our concern for social salience derives from the fact that the most 
common and most grievous cases of discrimination are those that affect socially salient group, i.e. that it is a property which helps us focus on those forms of discrimination most in need of redress. But it is not clear that social salience constitutes a necessary or sufficient condition for the moral wrongness of discrimination. Rather, it seems there could be both morally wrongful cases of idiosyncratic discrimination and morally benign cases of non-idiosyncratic discrimination, on any plausible theory of what makes discrimination morally wrong.

Second, we can imagine cases like Mogul Misogynist that involve two intersecting socially salient groups, such as:

Bigoted misogynist. A factory is purchased by a wealthy financier, who reviews the personnel records, and finds that about half the workers are male and half female, and that male workers are Monotheism-One believers ( $\mathrm{M}_{1}$-theists), while female workers are Monotheism-Two believers $\left(\mathrm{M}_{2}\right.$-theists $) .{ }^{21}$ The mogul then proceeds to order the $\mathrm{M}_{2}$-theists fired and replaced with $\mathrm{M}_{1}$ theists.

Here, a protected groups condition gives us no grounds for preferring to describe the situation as direct discrimination against M2-theists rather than indirect discrimination against women, or vice versa. Rather, it seems there is no reason not to consider it to constitute both. But if cases can still be both at once, then the protected groups-condition is no help in meeting the definitional desiderata.

What of the opposite scenario, i.e. one that affects no socially salient group either directly or indirectly? Consider:

Idiosyncratic indirect discriminator. A factory is purchased by a wealthy financier, who reviews the personnel records, and orders that employees born on a

\footnotetext{
${ }^{21}$ Some might balk at supposing a coincidental overlap between the two sets of properties. While principally the case is pertinent even if it is statistically unlikely, it need not be unrealistic. We can imagine that the highly correlated distribution arises e.g. because the Monotheism-One minority is generally poor and working class, with patriarchal values that mean that Monotheism-One women are generally pressured to stay at home, whereas the Monetheism-Two minority is generally prosperous and middle-class, with patriarchal values that mean that, while both genders are expected to join the labour market, boys are generally pushed to pursue advanced studies and girls are generally given no more than primary education. The situation among Protestants and Catholics in Europe may have approximated this, at certain points in history. But even if this still seems farfetched, I do not think the relevance of the case relies on it being more or less realistic.
} 
weekday (Mon-Fri) be fired and replaced with persons born during a weekend. The city runs two maternity wards, one of which operates during weekdays, the other on weekends. As a result, all of the persons born at "weekday"-ward are dismissed.

While this is unquestionably a strange case of discrimination, and perhaps a morally unproblematic and therefore uninteresting one, it does not strike me as obviously nonsensical to say that it constitutes indirect discrimination against the idiosyncratic group of "persons born at the "weekday"-ward", as well, of course, as direct discrimination against those born on a weekday. Yet here, the protected groups condition would have us hold that there is neither.

I think it is preferable, therefore, to consider socially salient and idiosyncratic discrimination a different and potentially crosscutting subdivision of discrimination to the direct/indirect distinction.

\section{Do intentions matter?}

A third and perhaps the most promising suggestion for how to distinguish direct from indirect discrimination is to let the intentions of the discriminator determine the target of discrimination. ${ }^{22}$ Aside from potentially satisfying our definitional desiderate, an intention condition will presumably be an attractive feature to those who believe that the wrongness of discrimination is (at least partly) accounted for in terms of the mental-states of the agent. ${ }^{23}$ (Alexander 1992; Arneson 2006; Glasgow 2009)

Note first that any act of discrimination presumably requires the minimal sense of intentionality necessary to make it an act of an agent, as opposed to e.g. a muscle spasm. Exactly what and how much is required for this is controversial, and I shall not take sides here, since it is not this minimal sense which is at stake. Rather, there are two ways we can imagine the intention condition

\footnotetext{
22 Note that we may want to talk of e.g. laws or institutions discriminating despite their lack of the ability to form intentional mental states. Presumably this would then be the case when such laws or institutions embodied discriminatory intentions.

${ }^{23}$ Such accounts typically explain the wrongness in terms of disrespect, but there are disrespect-accounts which do not rely on the mental-states of the agents. Cf. Hellman, D. (2008). When Is Discrimination Wrong? Cambridge, Harvard University Press. There are, however, problems with both mental-state and disrespect-accounts of the wrongness of discrimination. Cf. Lippert-Rasmussen, K. (2006). "The Badness of Discrimination." Ethical Theory and Moral Practice 9: 167-185, Segall, S. (2012). "What's so bad about Discrimination?" Utilitas 24(1).
} 
working. First, it could be a supplementary condition, which adds to our above definitions by holding that only the discriminator's intended target can be discriminated against, but that apart from this whether a case of discrimination is direct or indirect is still determined by the features we have already defined. Second, it could be a decisive condition, so that any discrimination intended to be discriminatory, whatever other features it may have, is direct, and any unintentional discrimination, indirect. Consider:

Sly misogynist. A factory is purchased by a wealthy financier, who reviews the personnel records, and finds that about half the workers are male, and half female. The mogul intends to fire the female employees, but realises that this would violate anti-discrimination laws. To achieve his purpose, he instead orders two new assembly belts installed, the height of which requires employees to be at least $175 \mathrm{~cm}$ tall. The mogul then proceeds to order those $174 \mathrm{~cm}$ or shorter fired, which results in all of the female workers being dismissed and replaced by male workers.

Given the intention condition, this would be either a case of indirect discrimination against women, but not direct discrimination against short persons, if the condition is supplementary, or a case of direct discrimination against women, not direct discrimination against short persons nor indirect discrimination against women, if the condition is decisive. Neither version of the condition, unfortunately, strikes me as persuasive.

The first problem is that, that contrary to our intuitive responses, we would have to say about the cases discussed prior to sly misogynist, that it is in fact indeterminate whether they constitute direct or indirect discrimination, and that we should have been agnostic about them. This is because I deliberately did not specify the intentions of the agent. Recall Inadvertent Misogynist, which mirrors sly misogynist with the exception of containing no information about intentions. Supposing that intentions do matter, is this a case of direct or indirect discrimination? The answer is that we do not and cannot know. That seems unsatisfactory. It sounds like a case of indirect discrimination against women, irrespective of intentions. 
Furthermore, if intentions matter, one would expect them to matter because they concern the group being discriminated against. Consider:

\begin{abstract}
Stochastic sexist. A factory is purchased by a wealthy financier, who reviews the personnel records, and finds that about half the workers are male, and half female. The mogul intends to fire either the men or the women. To do so, he runs a computer programme, which randomly selects either the male or the female workers, and fires them. As a result, the female workers are dismissed and replaced with male workers.
\end{abstract}

As stated in the case, the mogul does not intend to discriminate against women. He has, rather, a disjunctive intention to discriminate against either women or men. Yet it seems natural to say that it remains a case of discrimination, and a case of direct discrimination, although one which had an equal chance of becoming direct discrimination against either of the two groups. ${ }^{24}$

Finally, supposing intentions matter, what are we to think of cases where there are no intentions at all? Consider:

Unintended misogynist. A factory is purchased by a wealthy financier, who reviews the personnel records, and finds that about half the workers are male, and half female. The mogul then runs a computer programme, in order to randomly select half the workers and fire them. However, a keystroke-mistake makes his selection gender-based instead of random. As a result, the female workers are dismissed and replaced with male workers. ${ }^{25}$

A decisive intention condition will say either that this is indirect discrimination, or, like a supplementary intention condition, that it is not discrimination at all. Neither seems right. The former because apart from intentionality it shares all relevant features with Mogul Misogynist,

\footnotetext{
${ }^{24}$ Note that we can assume, if we prefer, that this is a process that the mogul applies every time he purchases a factory, and/or that the number of properties at stake is larger, i.e. that the random decision procedure picks one property among male, female, white, black, Christian, Atheist, right-handed, left-handed, born on a weekday, born on a weekend, etc., extending the list for as long as we like.

${ }^{25}$ Note that knowing that the agent has no relevant intention is different from not knowing whether or not the agent had any relevant intention, and if so what it was. The latter is the situation with respect to the first many cases I have used. The former is the case here.
} 
while lacking features that otherwise characterise cases of indirect discrimination. The latter because, while it is possible to say that the above does not constitute discrimination, doing so sounds odd and cuts an awkward distinction between two conceptually and, arguably, morally similar phenomena. ${ }^{26}$

The lesson of these cases, I believe, is that the selection mechanism of discrimination, i.e. the criterion of differential treatment, can come apart from the intention of discrimination, and that both can come apart from the disadvantageous effect of discrimination.

\section{Does wrongness matter?}

In the above, I investigated three criteria for distinguishing between direct and indirect discrimination, and concluded that none of them do well. A fourth solution might be to make moral wrongness the condition which determines whether it is one or the other. ${ }^{27}$ That is, the wrongness condition holds that a case which meets the prior conditions is a case of discrimination only if it wrongs the potential discriminatees, and if so a case of discrimination against those wronged.

This solution has both strengths and weaknesses. In its favour, it may fit with and explain our intuition that e.g. Inadvertent Misogynist is a case of indirect discrimination against women not direct discrimination against the less-than-175cm'ers, if, as many will likely find plausible, an argument can be made that the two differ in terms of wrongness. In addition to enabling this distinction, it may well be a better lexical definition, i.e. 'discrimination' is commonly used to denote actions that are morally wrong, and many persons will resist labelling actions which meet the other conditions as discriminatory, if their assessment is that the action is permissible.

Against the solution, I hold two points. First, that by moralising the definition, we draw a conceptual distinction between related phenomena that may blind us to the similarities. All else

\footnotetext{
${ }^{26}$ This is not to assume that the two are equally wrong - intentions may, as some would argue, matter for the permissibility of an action - only that they share a number of conceptual and morally relevant features.

${ }^{27}$ Since we are now exploring the role played by moral wrongness in discrimination, I should emphasize that, although I do not want to assume a particular account, I do assume, when I speak of discrimination being morally wrong, that it is only pro tanto wrong. Most moral theories will accept that there could be situations in which an act of discrimination is all things considered permissible (or even required), even if some feature of the act of discrimination gives rise to at least one reason against performing it.
} 
equal, it would seem preferable to preserve a descriptive definition of discrimination and settle the issue of moral wrongness after we have classified a situation as a case of discrimination or not. And if we do reserve the term 'discrimination' for the morally wrong subset of the actions defined in the preceding, we ought at least to introduce a term for the remaining cases.

Second, and more importantly, the wrongness condition introduces new difficulties, although they vary depending on whether we conceive of it as a subjective or objective condition. A subjective version holds that the wrongness at stake is perceived wrongness, an objective that the wrongness at stake is the actual moral wrongness independent of any perceptions. Given what I think is the plausible assumption that perceptions of wrongness are fallible, the subjective and objective versions will at least occasionally come apart.

Let us consider the two individually. The subjective version suffers from three problems. First, perceptions of wrongness can conflict, and the subjective wrongness condition will hold that whether or not something is a case of discrimination will similarly vary from person to person. That is, an instance of disadvantageous treatment that meets the former conditions can at one and the same time be a case of discrimination and not a case of discrimination. Second, given that the objective wrongness of discrimination is one of the most important features of a case of wrongful discrimination, the dubious fit between a subjective moralised conception and this feature seems to me a serious cost. Third, the subjective version is implausibly resistant to revised perceptions of wrongness. Suppose one holds a moralised conception of discrimination, and becomes persuaded that a situation which one had thought instantiated it, was not, in fact, a case of moral wrong. Surely, one would not want to maintain that it was discrimination when one thought it wrong, but no longer is? Rather, we would want to say that it was never, in fact, a case of discrimination, which suggests that it is actual, not perceived, wrongness that matters.

The objective version meanwhile comes at the cost of the fit with how we intuitively might want to apply the term that was supposed to justify its introduction in the first place. Since our perceptions of wrongness are both conflicting and fallible, then there will be cases that are in fact wrong and hence discrimination, although common usage would not label them such, and cases that are in fact not wrong and hence not discrimination, although common usage would hold them to be. If the motivation for introducing a wrongness condition is to provide a 
lexically superior definition, then the objective version may have modest success in achieving this aim.

Furthermore, since labelling a case as discriminatory on the objective version hinges on actual wrongness, we will be unable to determine whether any actual cases are or are not instances of discrimination until we settle the theoretical issue of what makes discrimination wrong. While not a principled reason for rejecting the wrongness condition, this is at least inconvenient, given the current state of disagreement in the literature.

Finally, although the wrongness condition will probably help us with some cases, it is not clear that it can completely eliminate the overlap of direct and indirect discrimination cases. The cases that remain both direct and indirect discrimination will differ depending on which theory of the wrongness of discrimination one accepts. However, it seems clear that no matter which of the plausible wrongness-accounts we adopt, we can construct cases where e.g. both groups are protected minorities, suffer disadvantage, are disrespected, etc.

Ultimately, I take the problems of the subjective version to be far the greater of the two. This leaves us with two options, neither of which is entirely satisfying. We can accept a descriptive definition of indirect discrimination which cannot meet the third definitional desiderata, in that it cannot hold direct and indirect discrimination to be mutually exclusive. Cases such as Inadvertent Misogynist will instantiate both, albeit against different (if overlapping) groups. Or, we can moralise the definition by introducing an objective wrongness condition, which will allow us to exclusively classify some otherwise problematic cases as either direct or indirect discrimination. But, doing so requires us to specify what the wrongness of discrimination consists in, is unlikely to perfectly match a lexical definition, and cannot decide cases in which both groups are wronged.

\section{When is equal treatment wrong?}

Throughout all of the preceding, I have been discussing a descriptive conception of discrimination. Perhaps the most important issue for conceptualising discrimination, however, is figuring out when and why discrimination constitutes a moral wrong, particularly if, as 
suggested above, a moral wrongness condition is supposed to help us determine whether or not a potential case even constitutes discrimination.

At first glance, the suggestion that there could even be such a thing as wrongful equal treatment may seem odd. Yet, intuitive cases are easy to produce. The judge who convicts everyone, both guilty and innocent, or the professor who fails both those of her students who merit a passing grade and those who do not, might serve. ${ }^{28}$ Such examples do not explain the wrongness of indirect discrimination, however. The wrongness of indirect discrimination against a group is, it seems reasonable to suppose, tied to the disadvantage conferred on the discriminatees. Recall that we earlier distinguished between two senses in which equal treatment could disadvantage discriminatees: either because a greater proportion of P-persons than of $\neg$ P-persons are negatively affected by the treatment, or because P-persons are more severely affected than $\neg \mathrm{P}$ persons by the treatment. The question, therefore, is whether either of these is connected to moral wrongness.

Let us consider first the issue of proportional disadvantage. For this to be wrong, there would have to be a non-instrumental reason to ensure that any distribution of advantages and disadvantages falls equally on the groups subject to the distribution. But this is implausible. We rightly do not worry about e.g. whether a policy will affect more people with three-syllable first names or two-syllable first names, and were there no other considerations at stake, we ought similarly not to worry about distributions across gender, race, religion, etc. (cf. LippertRasmussen 2008)

There may, of course, be other reasons why an unequal distribution between groups is morally troubling. Thus, Larry Alexander argues that, while there is no non-instrumental reason for distributing the same (uneven) portions of goods among otherwise equal individuals one way or the other when the preferences of the discriminator governing the distribution are benign, the morality of such discrimination depends on the justifiability of these preferences and changes if

\footnotetext{
${ }^{28}$ Recall that, while on a patient-centred interpretation of treatment these cases can be equally well described as equal and unequal treatment, on the agent-centred interpretation I have argued in favour of, they constitute equal treatment, since it is not necessary for the agent to distinguish between the two groups.
} 
their moral status does. ${ }^{29}$ (Alexander 1992; cf. also Arneson 2006) Similarly, egalitarians, prioritarians and sufficientarians may hold such distributions to be morally problematic if they place burdens on persons who ought not to be burdened, because doing so will increase inequality, place the burdens on the worse off rather than the better off, or shift the persons below the sufficiency line respectively. But these are not issues that arise from discrimination, rather they come from principles of distribution across groups defined by e.g. their welfare-, capacity- or opportunity-levels, and explaining the wrongness in terms of discrimination seems to add nothing to, while potentially confusing, the traditional debates of distributive justice.

The alternative understanding of disadvantage concerns severity of effect, that is, a group is disadvantaged if, irrespective of the proportions involved, P-persons are more severely affected than $\neg$ P-persons by treatment. This is the case in Unisex Healthcare, where all patients benefit from medical treatment but some pay a price in shame for the benefit, and might be the case in Parental Leave and Inadvertent Misogynist if e.g. the women who lose their jobs due to discrimination on the grounds of height are more socio-economically vulnerable than men affected by the same discrimination. And although Neighbourhood Schools as stated is silent about the broader status of blacks and whites, it is tempting to assume that a situation which contains the type of racially divided neighbourhoods described will also be one in which black children are generally from poorer, less educated homes, and that they may therefore suffer comparatively greater disadvantage from worse schools than white children.

Can imposing such comparatively greater disadvantage be morally wrong? Suppose, as I think highly plausible, that how an action affects the welfare of moral patients matters to its permissibility, and that therefore it matters to the wrongness of discrimination whether and if so to what extent it decreases the welfare of discriminatees, ${ }^{30}$ i.e harms them. ${ }^{31}$ Note however,

\footnotetext{
${ }^{29}$ As it turns out, Alexander is moderately sceptical about putting the burden of distributing goods in the optimal way on moral agents, and certainly opposed to most forms of legal prohibitions. Alexander, L. (1992). "What Makes Wrongful Discrimination Wrong? Biases, Preferences, Stereotypes and Proxies." University of Pennsylvania Law Review 141: 149-219. Here, although I think there are legitimate concerns about whether and in what shape to institutionalize such requirements in law, I am much less concerned than Alexander about the moral burdens placed on individuals.

30 This is somewhat of a simplification, because it avoids the question of what the relevant baseline for individuals' welfare is. If it is determined e.g. that the target of an action of disadvantageous differential treatment currently enjoys goods that although beneficial to her welfare ought properly to be otherwise distributed, then although her welfare may be reduced as compared to her level prior to the action, this reduction brings her closer to the level that she ought to enjoy, and is arguably not morally wrong, and thus not discrimination. Cf. Lippert-Rasmussen, K. (2007). "Private Discrimination: A Prioritarian

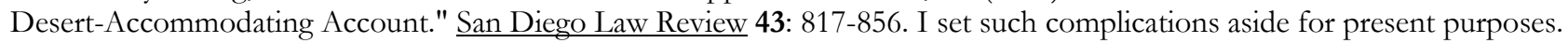


that in so doing we need to set aside any extrinsic harm, and focus on the harm caused by discriminating, rather than the individual acts of which discrimination is composed. To illustrate, the judge who convicts everyone will be doing harm to both the guilty and the innocent (arguably permissibly so, in the cases of the former), simply by virtue of imposing punishment, but this harm does not result from discrimination.

We can, however, classify at least the following three ways in which indirect discrimination might harm discriminatees: First, differing severity of effect may occur as a consequence of the differing preferences of discriminatees. Clearly, to restate the earlier example, if I serve pork to both those who enjoy it and to their Jewish, Muslim and vegetarian fellows, I am failing to take into account that the two groups have differing dietary preferences, and that my choice of cuisine is incompatible with meeting those of the latter. ${ }^{32}$

Second, the discrimination may put discriminatees in a situation in which the welfare cost of satisfying (or failing to satisfy) their similar preferences differs. If, as is still the case in most parts of the world, women are socio-economically vulnerable compared to men, then although their treatment in Inadvertent Misogynist is in one sense no worse than the treatment of short men - both parties lose their job because they are less than a certain height - their resulting and similar preferences will be more costly for women to fulfil. The psychological blow of losing a job, the ordeal of the search to find another, and the struggle to make your daily life continue to function both socially and economically while you are unemployed, will all be more difficult for women if the group is socio-economically vulnerable.

Third, the treatment of the two groups may cause symbolic harm. That is, the way equal treatment disadvantages a group, and the indifference, or even worse malice, implied by carrying out the treatment regardless, may send a signal that discriminatees are in some respect

\footnotetext{
${ }^{31}$ Some might want to describe the harms of discrimination in terms other than the impact on welfare of the discriminatee, such as e.g. placing restrictions on the opportunities available to persons. Cf. Moreau, S. (2010). "What is discrimination?" Philosophy \& Public Affairs 38(2): 143-179. I do not mean to argue for or against a particular conception of harm in the present. My point can, I believe, be carried through with suitable modifications of the examples for alternative accounts of harm.

${ }^{32}$ Note that it may be the case that I meet neither group's preferences perfectly - perhaps the pork-eaters are pisciphiles, who would much rather have enjoyed a tuna-steak - so long as the difference in preferences means that one group's preferences are better served than the other's. Also note that some might prefer to classify this as failing to benefit rather than harming. As previously noted, I do not wish to argue for a particular theory of harm in the present, since I believe my point about the type of harm potentially caused by indirect discrimination stands on alternative theories of harm, even if it may then require a different example for illustration.
} 
inferior. Such symbolic actions can be insulting to discriminatees as well as creating or reinforcing prejudices about the target-group, which are likely themselves to be at least instrumentally bad. Thus, the harm at stake is symbolic by means, not by nature, and very real. The risk of causing symbolic harm is particularly significant when the group in question is a socially salient group, and even more so when there is a history of prejudice and discrimination against the group. ${ }^{33}$

It is worth emphasizing that in the light of the above we can explain why gender is at once, under normal circumstances, morally irrelevant, and relevant to cases of discrimination like Inadvertent Misogynist. Ultimately, the group with which we are concerned is not women, even if they happen to figure disproportionately in the group of those hit hardest by indirect discrimination, but those persons, men or women, who are harmed. Women, if this is the case, can serve at most as a proxy property, directing attention to where we might start looking for those who have been disadvantaged. The wrongness occurs, not because the agent applies a morally neutral distinction in an amoral way, but because she fails to appreciate and act upon a morally relevant distinction, and in so doing causes avoidable harm. What makes indirect discrimination wrongful is that it harms those with particular vulnerabilities, not that it affects any particular group. ${ }^{34}$

\section{Conclusion}

Anatole France famously quipped that: “...la majestueuse égalité des lois [...] interdit au riche comme au pauvre de coucher sous les ponts, de mendier dans les rues et de voler du pain." 35 (France 1906) The sting of the quip lies, I think, in its exhibition of the callousness of formal

\footnotetext{
33 This, I believe, is in fact one of the two main reasons that our intuitions tend to emphasize discrimination of protected groups, the other being the far greater likelihood that these groups will be subject to discrimination. One might add that such groups will typically be socio-economically vulnerable in a way which makes them susceptible to harms resulting from inegalitarian distributions, but this is at once true of many groups not traditionally placed on the list of protected groups, and not true for at least some of the groups often placed there, so I take it to be less crucial in driving our intuitions.

${ }^{34}$ For a related, but much overlooked, point that uses an analysis along these lines to explain the disparity between racial discrimination and affirmative action, see Nickel, J. W. (1972). "Discrimination and Morally Relevant Characteristics." Analysis 32(4): 113-114..

35 This is slightly inaccurate: in truth Anatole France lets a lead character in the novel "Le lys rouge" state the quip as part of a longer rant on the pitiful state of French society. A fairly literal translation would read: "...the majestic equality of the laws $[\ldots]$ prohibits to rich as to poor to sleep beneath bridges, to beg in the streets, and to steal bread."
} 
equality in the face of grossly unequal conditions. We need to think carefully about what it is that troubles us about such callousness, the better to help ourselves and each other avoid it.

Indirect discrimination, I have argued, is disadvantageous equal treatment, where the distinction between differential and equal treatment (of P-persons) concerns whether the treatment requires that the agent distinguishes between $\mathrm{P}$-persons and $\neg \mathrm{P}$-persons. It is thus compatible with an agent treating two persons equally (as $\mathrm{P} / \neg \mathrm{P}$-persons) that she differentiates among them on the basis of whether they do or do not possess another property, $\mathrm{P}_{1}$. It is possible, therefore, on the definition I have proposed, to subject P-persons to indirect discrimination by an action that is in some other respect direct discrimination. This, after all, is the case in our much-used Inadvertent Misogynist - men and women are subjected equally to a procedure which discriminates against those shorter than $175 \mathrm{~cm}$. If we so desire, we can make the cut between the two cleaner by moralising the definition, a solution, however, which comes with both limited advantages and new problems.

As I have also attempted to argue, the difference between direct and indirect discrimination is a conceptual rather than a morally significant distinction. I see no reason to believe that it should make a difference to the moral wrongness (or rightness) of the agent's actions whether they are best understood as direct or indirect discrimination. As for explaining when indirect discrimination is wrong, the fact that it causes harm is a good candidate. And while not in itself an argument for a harm-based account of the wrongness of discrimination, I believe the way the account can explain (some of) our intuitions about the cases lends indirect support to it.

Finally, the analysis of indirect discrimination suggests that we may need to take more account of how our actions affect the welfare of others than we are sometimes wont. Our moral responsibilities may be wider and more demanding than we sometimes assume. This seems to me an entirely plausible conclusion.

\section{References}

(1971). Griggs vs Duke Power Co., US Supreme Court. 401 US 424.

Alexander, L. (1992). "What Makes Wrongful Discrimination Wrong? Biases, Preferences, Stereotypes and Proxies." University of Pennsylvania Law Review 141: 149-219.

Altman, A. (2011). Discrimination. Stanford Encyclopedia of Philosophy. E. N. Zalta. 
Arneson, R. J. (2006). "What is Wrongful Discrimination?" San Diego Law Review 43: 775-808. Campaign, F. D. A. D. (2003). "What is Discrimination." Retrieved 20 April, 2009, from http://www.stop-discrimination.info/46.0.html.

Connolly, M. (2006). Discrimination Law. Suffolk, Sweet \& Maxwell Ltd.

Doyle, O. (2007). "Direct Discrimination, Indirect Discrimination and Autonomy." Oxford Journal of Legal Studies 27(3): 537-553.

Dworkin, R. (2005). Taking Rights Seriously. London, Gerald Duckworth \& Co. Ltd.

Edmonds, D. (2006). Caste Wars - A Philosophy of Discrimination. Abingdon, Routledge.

Ezorsky, G. (2001). Discrimination. Encyclopedia of Ethics. C. B. Becker and L. C. Becker. New York, Routledge: 413-416.

France, A. (1906). Le lys rouge. Paris, Calmann-Lévy.

Gardner, J. (1996). "Discrimination as Injustice." Oxford Journal of Legal Studies 16:3: 353367.

Glasgow, J. (2009). "Racism as Disrespect." Ethics 120: 64-93.

Halldenius, L. (2005). "Dissecting Discrimination." Cambridge Quarterly of Healthcare Ethics 14: 455-463.

Heinrichs, B. (2007). "What is Discrimination and When is it Morally Wrong?" Jahrbuch für Wissenschaft und Ethik 12: 97-114.

Hellman, D. (2008). When Is Discrimination Wrong? Cambridge, Harvard University Press.

Lippert-Rasmussen, K. (2006). "The Badness of Discrimination." Ethical Theory and Moral Practice 9: 167-185.

Lippert-Rasmussen, K. (2007). Discrimination: What is it and What Makes it Morally Wrong? New Waves in Applied Ethics. J. Ryberg, C. Wolf and T. S. Petersen. Chippenham and Eastbourne, Palgrave Macmillan: 51-72.

Lippert-Rasmussen, K. (2007). "Private Discrimination: A Prioritarian Desert-Accommodating Account." San Diego Law Review 43: 817-856.

Lippert-Rasmussen, K. (2008). "Discrimination and the Aim of Proportional Representation." Politics, Philosophy \& Economics 7: 159-182.

Lippert-Rasmussen, K. (2013). Born Free and Equal? Oxford, Oxford University Press.

McCrudden, C. (1982). "Institutional Discrimination." Oxford Journal of Legal Studies 2(3): 303-367.

Moreau, S. (2010). "What is discrimination?" Philosophy \& Public Affairs 38(2): 143-179.

Nickel, J. W. (1972). "Discrimination and Morally Relevant Characteristics." Analysis 32(4): 113-114.

Radcliffe Richards, J. (2000). Practical Reason and Moral Certainty - the Case of Discrimination. Reasoning Practically. E. Ullmann-Margalit. Oxford, Oxford University Press: 151-163.

Segall, S. (2012). "What's so bad about Discrimination?" Utilitas 24(1).

Wertheimer, A. (1983). "Jobs, Qualifications and Preferences." Ethics 94: 99-112. 